\title{
Desempenho de Workflows Multithreading no Supercomputador SDumont em Experimentos de RNA-Seq
}

\author{
Lucas Cruz $^{1,2}$, Micaella Coelho ${ }^{2}$, Luiz Gadelha ${ }^{2}$, Kary Ocaña ${ }^{2}$, Carla Osthoff ${ }^{2}$ \\ ${ }^{1}$ Centro Federal de Educação Tecnológica Celso Suckow da Fonseca (CEFET/RJ) \\ Petrópolis - RJ - Brasil \\ ${ }^{2}$ Laboratório Nacional de Computação Científica (LNCC) \\ Petrópolis - RJ - Brasil \\ \{lucruz, micaella, lgadelha, karyann, osthoff\}@lncc.br
}

\begin{abstract}
This article presents a comparative analysis of the performance of the scientific workflow ParslRNA-Seq, on the Parsl and Bowtie parallelization parameters, in order to guarantee the rational use and efficient allocation of computational resources in the Santos Dumont Supercomputer.
\end{abstract}

Resumo. Este artigo apresenta uma análise comparativa de desempenho do workflow científico ParslRNA-Seq, sobre os parâmetros de paralelização do Parsl e do Bowtie, a fim de garantir o uso racional e alocação eficiente dos recursos computacionais no Supercomputador Santos Dumont.

\section{Introdução}

A técnica de Sequenciamento de RNA (RNA-Seq) é utilizada nas análises de expressão de genes do transcritoma, para o estudo de um conjunto de transcritos de uma célula em uma dada condição fisiológica ou de desenvolvimento, como o câncer. Na bioinformática, a modelagem de experimentos de RNA-Seq é um desafio devido à complexidade, manipulação de grandes volumes de dados e pelo custo computacional. Workflows científicos são abstrações que representam esses experimentos como um fluxo encadeado de atividades que são executadas por aplicações com diversas características, dentre as quais a de Computação de Alto Desemepenho (CAD). Com o uso de sistemas de gerência ou linguagens de programação é possível modelar, gerenciar e analisar os workflows.

Este artigo é uma extensão de [Cruz et al. 2020] o qual apresenta a modelagem do workflow ParslRNA-Seq e uma análise exploratória sobre como o workflow utiliza os recursos computacionais. O presente trabalho apresenta análises acerca das execuções multithreading, sob uso de arquitetura CPU multicore Ivy Bridge, da atividade intitulada Bowtie, executada pelo software Bowtie2 e do Parsl, biblioteca Python utilizada para modelar e executar o workflow. Com execuções multithreading podem haver competições no uso dos recursos computacionais disponíveis, fazendo-se necessário estudar a melhor configuração de parâmetros multithreading do Bowtie e de paralelismo de tarefas do Parsl. O objetivo deste trabalho é prover uma análise comparativa de desempenho nas execuções multithreading do workflow ParslRNA-Seq em ambientes de CAD, mais especificamente no supercomputador Santos Dumont ${ }^{1}$ (SDumont), para levar ao usuário a melhor configuração de parâmetros entre o paralelismo multithreading e de tarefas.

Agradecemos ao LNCC (MCTI, Brasil) por prover os recursos do supercomputador SDumont e pelo apoio financeiro do Conselho Nacional de Desenvolvimento Científico e Tecnológico.

${ }^{1}$ Disponível em: https://sdumont.lncc.br/. Último acesso: 24/11/2020. 


\section{Trabalhos Relacionados}

Em [Cruz et al. 2020] são realizados experimentos para avaliar a melhor configuração de parametrização multithreading do workflow ParsIRNA-Seq, entre o Parsl e a aplicação Bowtie, para um conjunto de 6 arquivos de entrada. A conclusão do estudo é de que para arquivos de tamanhos similares aos utilizados e arquitetura similar à CPU Ivy Bridge Intel Xeon com 64 GB de memória RAM, a melhor configuração seria 12 no parâmetro de paralelização de tarefas do Parsl em conjunto com 24 threads da paralelização do Bowtie. $\mathrm{O}$ artigo também apresenta experimentos que demostram que os diferentes tamanhos entre os arquivos de entrada causam um desbalanceamento de carga e uma baixa eficiência na utilização das CPUs. O presente trabalho realiza os mesmos experimentos, porém para arquivos de entrada com tamanhos maiores e utiliza a mesma metodologia para avaliar a melhor configuração para o paralelismo de tarefas do Parsl e de threads do Bowtie.

\section{Metodologia}

Para execução desse workflow foi utilizado um nó computacional do supercomputador SDumont composto por duas CPUs Ivy Bridge Intel Xeon E5-2695v2 (12c @2.4GHz) e 64 GB de memória RAM. Para a realização das análises de desempenho foram consideradas as médias dos tempos de três execuções, onde o número de threads variam de 1 a 24 e a quantidade de tarefas paralelas é equivalente a quantidade de arquivos de entrada dentro dos cenários descritos a seguir: O primeiro cenário, propõe uma execução paralela das tarefas apenas com o Parsl; O segundo cenário, faz execução paralela do Bowtie, fazendo com que a execução do Parsl seja serial, portanto, as demais tarefas componentes do workflow não são paralelizadas; No terceiro cenário, há uma paralelização de dois níveis, com o paralelismo de tarefas do Parsl e o multithreadig do Bowtie. Uma análise final é realizada, estendendo o melhor cenário observado, para um maior volume de dados.

\section{Resultados}

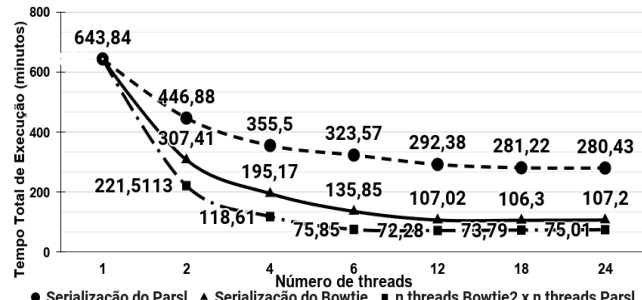

(a) TTE

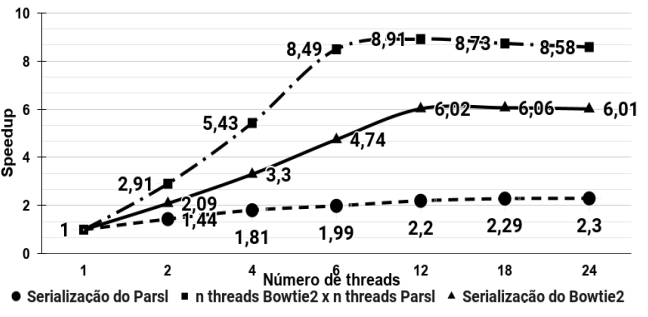

(b) Speedup

Figura 1. TTE e Speedup dos cenários de paralelização.

Os três cenários experimentais levantados na seção 3 são apresentados na Figura 1. 1(a) apresenta o Tempo Total de Execução (TTE) e 1(b) o speedup. As execuções foram realizadas para um conjunto de 6 arquivos de entrada, que possuem tamanhos entre 1.5 GB e 2.6 GB totalizando e gerando cerca de 11 GB e 54 GB de dados, respectivamente. A curva contínua traz a execução do primeiro cenário, indicando o melhor TTE de 106,3 minutos e speedup de 6,06 com 18 threads. A curva tracejada é referente ao segundo cenário, o melhor TTE é indicado em 24 threads, com 280,43 minutos e speedup de 2,3. O terceiro cenário é apresentado pela curva travessão-ponto com melhor TTE 
de 72,28 e speedup de 8,91, indicado em 12 threads. Para os três cenários o ganho de desempenho do workflow demonstra uma tendência de estabilização a partir de 12 threads. Isso é devido ao número de dados de entrada fornecidos pois, como observado em [Cruz et al. 2020], o maior número de núcleos de CPUs utilizadas durante grande parte do tempo de execução do workflow será equivalente ao número de arquivos de entrada. Também é possível observar a partir dos resultados apresentados na Figura 1, que com a paralelização conjunta entre o Parsl e a aplicação Bowtie2, referente ao terceiro cenário, haverá maior eficiência no uso dos recursos computacionais disponíveis.

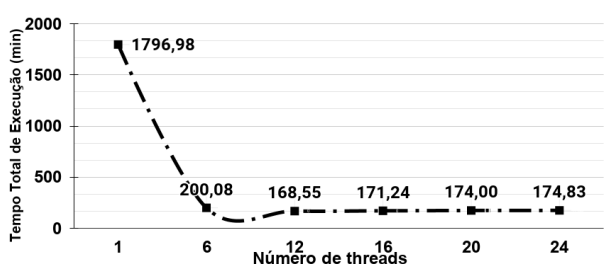

(a) TTE

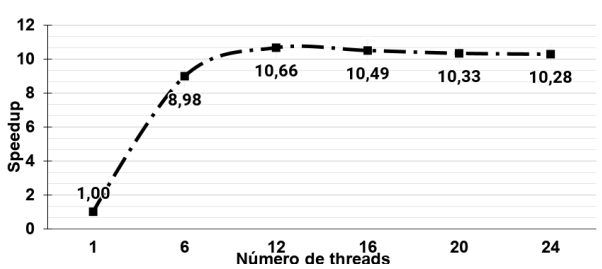

(b) Speedup

Figura 2. TTE e Speedup das execuções para um maior volume de dados.

Como destacado na seção 3 foi feita uma extensão para análise do terceiro cenário, o melhor dentre os três sugeridos, que é apresentada na Figura 2, TTE 2(a) e speedup 2(b). O volume total de dados de entrada utilizado foi quase o dobro do que foi utilizado nas análises da Figura 1. As execuções foram realizadas para um total de 8 arquivos de entrada que possuem tamanhos variando entre $1.8 \mathrm{~GB}$ e $4.1 \mathrm{~GB}$ totalizando e gerando, respectivamente, cerca de 23 GB e 135 GB. O melhor TTE foi de 168,55 minutos e o speedup de 10,66 indicados em 12 threads. A comparação de speedup entre o terceiro cenário da Figura 1 com o da Figura 2, que utiliza o dobro do volume de dados, indica que há uma maior distribuição de trabalho entre os núcleos devido ao número e volume de dados fornecidos, diminuindo o número de núcleos ociosos durante a execução.

\section{Conclusão}

As análises comparativas entre os cenários apresentados mostram que os melhores resultados são alcançados no terceiro cenário quando há o uso conjunto do recurso multithreading do Bowtie e do paralelismo de tarefas do Parsl, tendo a melhor configuração de parametrização apresentada quando o número de threads é igual a 12. No entanto, é necessário levar em consideração que com a alteração do número e volume de dados a melhor configuração de threads pode variar. Além disso, os resultados indicam que quanto maior for o volume e número dos arquivos de entrada, melhor será a eficiência no uso das CPUs. Como passos futuros serão realizadas análises sobre as execuções em múltiplos nós e o workflow ParslRNA-Seq, após otimizado, será disponibilizado para uso da comunidade científica através do portal de bioinformática Bioinfo-Portal ${ }^{2}$.

\section{Referências}

Cruz, L., Coelho, M., Gadelha, L., Ocaña, K., and Osthoff, C. (2020). Avaliação de desempenho de um workflow científico para experimentos de rna-seq no supercomputador santos dumont. In Workshop de Iniciação Científica do XXI Simpósio em Sistemas Computacionais de Alto Desempenho. (Aceito em processo de publicação).

\footnotetext{
${ }^{2}$ Disponível em: https://bioinfo.lncc.br/. Último acesso: 24/11/2020.
} 